\title{
Optic nerve injury upregulates retinoic acid signaling in the adult frog visual system.
}

Mildred V. Duprey-Díaz ${ }^{1,2}$, Jonathan M. Blagburn ${ }^{2}$ and Rosa E. Blanco ${ }^{1,2}$

${ }^{1}$ Department of Anatomy and Neurobiology, School of Medicine, University of Puerto Rico, San Juan, PR, USA

${ }^{2}$ Institute of Neurobiology, University of Puerto Rico Medical Sciences Campus, San Juan, PR, USA

Corresponding author:

Rosa E. Blanco

Email: rosa.blanco@upr.edu

Institute of Neurobiology

201 Calle Norzagaray

San Juan, PR 00901 


\section{Abstract}

Retinoic acid (RA) is important during development, in neuronal plasticity, and also in peripheral nervous system regeneration. Here we use the frog visual system as a model to investigate the changes in RA signaling that take place after axonal injury to the central nervous system. Immunocytochemistry was used to localize different components of RA signaling within sections of the retina and optic tectum, namely, the synthetic enzyme retinaldehyde dehydrogenase (RALDH), the RA binding proteins CRABPI and II, the retinoic acid receptors RAR $\alpha, \beta$ and (, and finally the catabolic enzyme CYP26A1. The levels of these proteins were quantified in extracts of retina and tectum using Western blotting. Animals were studied at 1 week, 3 weeks and 6 weeks after optic nerve transection. At the latter time point the RGC axons were re-entering the optic tectum. All the components of RA signaling were present at low to moderate levels in retinas and tecta of control, unoperated animals. In retina, soon after optic nerve injury there was a large increase in RALDH, some increase in the CRABPs, and a large increase in RGC RAR $\beta$ and (expression. These increases continued as the RGC axons were regenerating, with the addition of later RARa expression at 6 weeks. At no stage did CYP26A1 expression significantly change. In the tectum the levels of RALDH increased after axotomy and during regrowth of axons ( 3 weeks), then decreased at 6 weeks, at which time the levels of CYP26A1 increased. Axotomy did not cause an immediate increase in tectal RAR levels but RAR and RAR $\beta$ increased after 3 weeks and RAR( only after 6 weeks. These results are consistent with RA signaling playing an important role in the survival and regeneration of frog RGCs. 


\section{Introduction}

Retinoic acid (RA), the active metabolite and mediator of vitamin A function, is an important morphogen, signaling molecule, and transcriptional activator that plays a fundamental role in the regulation of neuronal differentiation and patterning during development (McCaffery and Dräger, 1994; McCaffery et al., 1999, 1992). Retinoic acid is synthesized by the enzyme retinaldehyde dehydrogenase (RALDH) from retinal (Napoli, 2012). Cellular retinoic acid binding proteins (CRABP-I and CRABP-II) aid in the transport of RA into the nucleus (Dong et al., 1999), where it binds with its receptors. These retinoic acid receptors (RARs), of which there are three subtypes, $\alpha, \beta$, and $\gamma$, belong to the steroid-thyroid hormone receptor family of transcription regulators (Bastien and Rochette-Egly, 2004). The complex formed by RA bound to its receptors interacts with retinoic acid response element sequences (RAREs), found in the promoter region of RA target genes, and activates and enhances transcription of those genes (Bastien and Rochette-Egly, 2004). Finally, the enzyme CYP26A1 regulates the degradation of $\mathrm{RA}$ (White et al., 1996).

After development is over, RA signaling has a role in the CNS of adult animals, particularly in areas of high neuronal plasticity such as the hippocampus, cortex, and striatum (Goodman et al., 2012; Maden, 2007; McCaffery et al., 2006; Shearer et al., 2012; Stoney et al., 2015; Thompson Haskell et al., 2002). It has also recently been implicated in the control of rhythms within the brain (Ransom et al., 2014). In addition, alterations in the expression of some of the components of RA signaling may contribute to the pathophysiology of various neurodegenerative diseases including ALS (Jokic et al., 2007; Kolarcik and Bowser, 2012) and Alzheimer's disease (Corcoran et al., 2004; Kawahara et al., 2014).

Of particular relevance to the present study, RA signaling also affects neuronal regeneration. Upregulation of RA signaling takes place after injury to rat peripheral nerves (Zhelyaznik and Mey, 2006; Zhelyaznik et al., 2003) and spinal cord (Mey et al., 2005), and ectopic expression of RAR promotes axonal regrowth (Wong et al., 2006; Yip et al., 2006). In the mammalian visual system, part of the CNS which does not regenerate, RAR $\beta$ is down-regulated after development and not expressed in the adult (Koriyama et al., 2014). In contrast, in the fish, where almost all retinal ganglion cells (RGCs) survive, regenerate and restore visual function, RA signaling components are upregulated after injury (Nagashima et al., 2009).

The frog visual system is similar to the mammal's in that many of its RGCs die after axotomy (Blanco et al., 2000), but like that of the fish in that the surviving RGCs are able to regenerate and reconnect with their targets in the optic tectum (Soto et al., 2006a, 2003). Both the survival rate, and regeneration speed, of the frog's RGCs can be augmented by application of growth factors to optic 
nerve or eyeball, and we have studied the molecular pathways involved (Blanco et al., 2008, 2000; Ríos-Muñoz et al., 2005; Soto et al., 2006b; Vega-Meléndez et al., 2014). In view of its potential importance in $\mathrm{RGC}$ regeneration, the question arises as to whether RA signaling is present in the adult frog visual system, and whether axotomy causes its upregulation (as in fish) or not (as in mammals). There are a few studies of RA in the frog visual system, however they pertain to its development (Lupo et al., 2005), and do not address the question of whether it persists in the adult. In this study therefore we describe the cellular localization, and quantify the amounts, of the different components of the RA signaling system in the adult frog retina and optic tectum, and determine whether their distribution changes after injury to the optic nerve.

\section{Methods}

\subsection{Animals}

Adult frogs (Rana pipiens) of both sexes were used. They were obtained from Connecticut Valley Biological Supply Company (Southampton, MA) and kept in tanks with recirculating tap water at $19^{\circ} \mathrm{C}$.

\subsection{Surgical technique for optic nerve axotomy}

Under $0.3 \%$ tricaine anesthesia the right eyeball of series of frogs (Rana pipiens) was approached from the palate and an incision made; the extraocular muscles were teased aside and the intraorbital section of the optic nerve was exposed. While avoiding large blood vessels, a hole was made in the meningeal sheath and the nerve within was severed, allowing a narrow, but complete, separation of the stumps within the intact sheath. The incision was sutured and the animal was allowed to recuperate. All protocols comply with $\mathrm{NIH}$ guidelines and were approved by the institutional animal care and use committee.

\subsection{Immunohistochemistry}

\subsubsection{Primary antibodies}

All antibodies used in this study were obtained from Santa Cruz Biotechnology and Abcam. In most cases they have not been previously tested in amphibian tissue. In the absence of any information on the DNA sequences of their respective genes in Rana, their specificity was assessed by several criteria: (1) a specific and robust staining pattern, which was (2) prevented by the supplied blocking peptide or by omitting the primary antibody, and (3) was consistent between different antibodies against the same protein. (4) Appropriately-sized band(s) in Western blots. (5) BLAST sequence similarity of the likely immunogenic region(s) (see Supplemental file), using a cutoff of $>65 \%$ similarity of positive scores (Scalia et al., 2015). Likely immunogenic regions were located within the given amino acid range by eliminating regions that were identical in closely-related but different proteins, 
and also eliminating regions with a low immunogenicity score as determined by the program AbDesigner (Pisitkun et al., 2012) (see Supplemental Excel file).

The primary antibodies were:

(1) ALDH1/2 (H85) (cat \# Sc-50385), polyclonal raised in rabbit against amino acids 186-270 of human retinaldehyde dehydrogenase (RALDH). This is reported by the manufacturer to recognize RALDH1/2 in species ranging from human to chicken. BLAST alignment of the likely immunogenic region shows 94-97\% similarity with amphibian RALDH1/2.

(2) CYP26A1 (F27 P6 A1) (cat \# sc-54618), monoclonal raised in mouse against the C-terminal region of human CYP26A1. Recognizes the human protein, also reported to recognize mouse CYP26A1 (Trasino et al., 2015). A different CYP26A1 antibody recognizes the protein in Xenopus (Thomas and Henry, 2014). BLAST alignment of 4 likely immunogenic regions shows $66-71 \%$ similarity with amphibian CYP26A1 in 3 of them.

(3) CYP26A1 (Abcam cat \# ab135521), polyclonal raised in rabbit against 47 C-terminal amino acids of human CYP26A1. Recognizes CYP26A1 in species ranging from human to pig. BLAST alignment of the likely immunogenic regions shows $77-79 \%$ similarity with amphibian CYP26A1.

(4) CYP26A1 (Abcam cat \# ab133949), polyclonal raised in rabbit against amino acids 125-155 of human CYP26A1. Recognizes CYP26A1 in human. BLAST alignment of the likely immunogenic regions shows $77 \%$ similarity with amphibian CYP26A1.

(5) CRABP-I (S-14) (cat \# SC-10061), polyclonal raised in goat against an internal region of human cytoplasmic retinoic acid e binding protein I (CRABP-I). Recognizes CRABP-I in species ranging from human to chicken. BLAST alignment of the likely immunogenic region shows $80-85 \%$ similarity with amphibian xCRABP/CRABP-I.

(6) CRABP-II (K-13) (cat \# SC-10065), polyclonal raised in goat against an internal region of human cytoplasmic retinoic acid binding protein II (CRABP-II). Recognizes CRABP-II in species ranging from human to pig. BLAST alignment of the likely immunogenic region shows $80-85 \%$ similarity with amphibian CRABP-II.

(7) RARa (L-15) (cat \# Sc-15040), polyclonal raised in goat against a C-terminal region of human retinoic acid receptor a (RARa). Recognizes RARa in species ranging from human to Xenopus. BLAST alignment of the likely immunogenic region shows $78-89 \%$ similarity with amphibian RARa. 
(8) RARa (C-20) (cat \# sc-551), polyclonal raised in rabbit against a C-terminal region of human retinoic acid receptor a (RAR $\alpha$ ). Recognizes RARa in species ranging from human to pig. BLAST alignment of the likely immunogenic region shows $78-89 \%$ similarity with amphibian RARa.

(9) RARß2 (H-55) (cat \# sc-14028), polyclonal raised in rabbit against amino acids 1-55 of human retinoic acid receptor $\beta 2$ (RARß2). Recognizes $R A R \beta 2$ in species ranging from human to pig. BLAST alignment of the likely immunogenic region shows $98-100 \%$ similarity with amphibian $R A R \beta / \beta 2$.

(10) RARY (G-1) (cat \# sc-7387), monoclonal raised in mouse against human retinoic acid receptor $\mathrm{Y}$ (RARY). Recognizes RARY in human and rodents. BLAST alignment of 5 likely immunogenic regions shows $70-73 \%$ similarity with amphibian RARY in 3 of them.

(11) RARY (C-19) (cat \# Sc-550), polyclonal raised in rabbit against a C-terminal region of human retinoic acid receptor $\mathrm{Y}$ (RARY). Recognizes RARY in human. BLAST alignment of likely immunogenic regions shows $71 \%$ similarity with amphibian $R A R Y$.

\subsubsection{Immunohistochemical methods}

The eye cups, optic nerves, and optic tecta of four animals $(n=4)$ were fixed with buffered $2 \%$ paraformaldehyde solution for $1 \mathrm{~h}$, washed with phosphate-buffered saline, and then placed in $30 \%$ sucrose for cryoprotection at $4^{\circ} \mathrm{C}$ overnight. After being frozen, cryostat sections of $12 \mu \mathrm{m}$ from both control and experimental tissues were cut and placed on the same slide, yielding approximately 15 slides. For immunocytochemistry, the sections were washed once for 30 min in phosphate-buffered saline (PBS) solution, and later incubated for $1 \mathrm{hr}$ in $10 \%$ normal goat serum. Tissue was then incubated overnight with polyclonal antisera RALDH, (CYP26A1, RARs $\alpha, \beta, \gamma$, and CRABP I and II, all at a dilution of $1: 200$ in 0.1 M PBS $+0.3 \%$ Triton X-100 $+0.5 \%$ bovine serum albumin. After several washes with $0.1 \mathrm{M}$ PBS the sections were incubated with goat anti-rabbit or anti-mouse lgG-CY3 (1:200, Jackson Immunoresearch Labs) for 2 hrs at room temperature. The sections were rinsed in PBS six times for 10 min each, and mounted in Polymount. Specificity of staining was tested by omitting the primary antibody and by preabsorption with their corresponding peptides, which resulted in the absence of all immunostaining. In order to try to ensure consistent antibody staining, frozen sections from control animals and from animals at different experimental times were processed together, using the same antibody dilutions.

Preparations were viewed and images acquired using a Zeiss Pascal, LSM 510 Meta Confocal Laser microscope (Carl Zeiss Inc), using the same objective lens (x40) and confocal settings for the different treatments. Detector gain was set so that the brightest pixels in the image of the most intensely- 
stained section on a slide were not saturated, then maintained constant throughout. Control and experimental sections were imaged with the same settings. For the figures, images were all given the same adjustment for maximal contrast, by setting the black point to the darkest pixel in the space below the retina, and ensuring that the white point was the brightest pixel in the image, either of the immunostaining where it was most intense or, when immunostaining was faint, of the brightest of the scattered punctate debris clusters. With these minor adjustments, background tissue staining (the lowest staining regions of the IPL or the ONL) was consistently about $10 \%$ of the maximum brightness. Plates were assembled using Adobe Photoshop (Adobe Systems, Inc.) and CorelDraw (Corel Corp.).

For the analysis of GCL immunoreactive intensity, images were taken from nasal and temporal areas of retinas of controls, and experimental animals and the staining intensity measurements were collected from cells in the GCL using ImageJ software (Wayne Rasband, NIH). The mean intensity of antibody staining within the outline was calculated, converting pixel values to a scale of 0 to 100 . Mean intensity measurements were also taken from the lowest staining region of the ONL and from the IPL; the lower of these two values was subsequently defined as the background staining intensity.

\subsection{TDA dextran amine retrograde labeling of RGCs}

A $1 \mathrm{~mm}$ square piece of cellulose acetate membrane filter $(0.8 \mu \mathrm{m}$ pore size; Schleicher and Schuell, Keene, $\mathrm{NH}$ ) was infused with a saturated solution of Texas Red dextran amine (TDA; 3,000 MW; Molecular Probes) in ethanol and left to air-dry so that particles of TDA were embedded within the filter. The optic nerve was exposed and cut close to the back of eyeball. The piece of filter was inserted into the stump, and the palate was sutured. After 48 hours, the frog was anesthetized, fixed and the retina was sectioned for immunocytochemistry as described above.

\subsection{Total protein isolation from retinal tissue}

Three extractions from control and experimental tissues were obtained, with each extraction using tissue pooled from two animals. There were thus 3 independent samples for each group. Isolated tissue was homogenized in lysis buffer containing $10 \mathrm{mM}$ Tris- $\mathrm{HCl} \mathrm{pH} 7.6,150 \mathrm{mM} \mathrm{NaCl}, 0.5 \%$ Nonidet P-40, 1 mM EDTA, 0.2 mM phenylmethylsulfonyl fluoride, 1/100 per volume of protease inhibitor cocktail $(0.1 \mu \mathrm{g} / \mathrm{mL}$ leupeptin, $0.001 \mu \mathrm{g} / \mathrm{mL}$ pepstatin, $0.1 \mu \mathrm{g} / \mathrm{mL}$ aprotinin), and 1/100 per volume of phosphatase inhibitor cocktail I and II (Sigma) using a motorized homogenizer. Cells were disrupted by sonication for $10 \mathrm{~s}$ (1 pulse per $\mathrm{s}$ at maximum power) using a Sonic Dismembrator (Fisher Scientific) at $4^{\circ} \mathrm{C}$. Samples were then left to stand for $30 \mathrm{~min}$ at $4^{\circ} \mathrm{C}$ and centrifuged at 14,000 rpm for $15 \mathrm{~min}$ at $4^{\circ} \mathrm{C}$. Protein concentration was determined using a Lowry-based assay from BioRad (DC-protein assay; Bio-Rad) and read in a spectrophotometer. 


\subsection{Western blotting}

Proteins were separated by sodium dodecyl sulfate-polyacrylamide gel electrophoresis. Approximately $50 \mu \mathrm{g}$ of total protein from each sample was separated in a 4-20 \% gel (Bio-Rad). Electrophoresed proteins were then transferred to a polyvinylidene difluoride membrane (Millipore) for 30 min and blocked for $1 \mathrm{~h}$. After blocking, the membranes were incubated overnight at $4^{\circ} \mathrm{C}$ with the following rabbit polyclonal antibodies against RARa, RAR, RARy (1:500, Santa Cruz Biotechnology), RALDH (1:400, Santa Cruz Biotechnology), a mouse anti-CYP26A1 (1:400, Santa Cruz Biotechnology), and a rabbit anti-GAPDH (1:3000, Novus Biologicals) diluted in blocking solution. Bound primary antibody was detected using a peroxidase-conjugated goat anti-rabbit or mouse secondary antibody (1:2000, Bio-Rad) for $2 \mathrm{~h}$ at room temperature. To visualize immunoreactive bands, membranes were developed for analysis using a chemiluminescence method (ECL Prime, GE Healthcare). Each set of Western blots was performed in duplicate for each one of the protein extractions. Images from the processed membranes were captured using the ISO400R Kodak Image Station Software (Kodak) and analyzed using the Image $\mathrm{J}$ program (Wayne Rasband, NIH). Relative intensities for protein signals were averaged from the duplicates and normalized against the average control value and GAPDH values. One-way ANOVA and post-hoc Tukey tests were performed to determine statistically significant changes.

\section{Results}

\subsection{RA signaling components are present in retinal ganglion cells.}

In order to first confirm that the different components of RA signaling, namely, the synthetic enzyme RALDH, and RARs $\alpha, \beta$, and $\gamma$, were indeed present in retinal ganglion cells (RGCs) we used Texas Red Dextran amine (TDA) retrograde labeling (Fig. 1). This showed that immunoreactivity against all these proteins was present in RGCs. It should be noted that the TDA backfilling procedure necessitates cutting the axons, so these results correspond to 2 days after axotomy.

\subsection{Axotomy changes RA signaling components in the retina.}

\subsubsection{RALDH and CYP26A1}

In control frog retinal sections, low stain levels for RALDH were observed, not only in RGCs, but also in the cytoplasm of a subpopulation of cells at the innermost region of the INL (Figure 2A, top row). Some RALDH staining was also detected in Müller cell-like processes, processes in sublaminae of the IPL, OPL, and in RGC axons in the NFL. RALDH immunoreactivity in cell bodies and processes appeared to increase after axotomy, with stronger staining compared to control retinas, particularly in the GCL and NFL (Figure 2B). Higher than normal staining levels for RALDH were sustained through the time points when regeneration is taking place (3-6 weeks post injury, Figure 2C). 
Western blot analysis was carried out to quantify the changes in the amount of RALDH protein after axotomy (Fig. 3). The RALDH antibody used in this study recognizes both isoforms RALDH1 and 2 in mammals (Burger et al., 2009) and BLAST analysis predicts that it also does so in frogs, thus we cannot distinguish between them. Immunoblot analysis showed that at one week after axotomy, RALDH levels increased by $83 \%$ over control values ( $<<0.0001)$, with an additional $46 \%$ increase at three weeks $(p<0.0005)$, followed by a $14 \%$ decline $(p<0.0001)$ at six weeks, albeit to levels that were still $1.3 x$ control values $(p<0.0001)$.

The cytochrome P450 26A1 is a member of the CYP450 monooxygenase family of proteins and a major RA catabolic enzyme (Lutz et al., 2009). Moderate levels of CYP26A1 immunoreactivity were detected in fibers of the NFL and OPL of control retinas (Figure 2D). The majority of the cell bodies at the GCL, and subpopulation of cells in the INL and ONL, and sublaminae of the IPL showed low levels of CYP26A1 immunostaining in control animals. Axotomy resulted in no obvious changes in CYP26A1 immunoreactivity (Figure 2E, F).

Two bands of approximately $49 \mathrm{kDa}$ molecular weight were detected on immunoblots using CYP26A antibody, which may indicate the existence of two isoforms of this enzyme in the frog visual system. Immunoblot analysis showed there was no significant change in retinal CYP26A1 levels after axotomy compared to controls (Figure $3 \mathrm{~B}$ ).

\subsubsection{CRABPI and II}

The actions of RA are dependent on the activity of two classes of proteins within the cell, one in the cytoplasm and the other in the nucleus. The cytoplasmic proteins are cellular RA-binding proteins I and II (CRABP I and CRABP II) and they function as chaperones that regulate the metabolism, signaling and transport of RA (Dong et al., 1999).

Both CRABP proteins were present in the normal adult frog retina. Low to moderate immunostaining of CRABPI was identified in subpopulations of cells in the INL, and in processes at the NFL (Figure 4A, control). CRABPI immunoreactivity was also found in Müller cell like processes. Cells in the INL were also immunoreactive for CRABPII. Low levels of CRABPI and II immunostaining were present in cell bodies located at the GCL of control retina (Figure 4A, D). After axotomy, the staining intensity in CRABPI and II immunoreactive cell bodies in the INL and in processes of the IPL appeared to increase (Figure 4B, E). Some increase in staining was also seen in the RGCs of the GCL.

The preponderance of immunostaining in layers other than the GCL made immunoblots less suitable for comparing the differences between axotomized and uninjured animals, so instead we quantified 
the staining intensities within the GCL itself (Fig. 4G). Axotomy greatly increased CRABPI staining intensity in the GCL at one week compared to uninjured retinas (Figure 4G, 60\% more at one week versus control values, $p<0.005)$, and this increase was maintained at later time points in regenerating retinas (Figure 4G, $p<0.005$ ). In contrast, CRABPII staining values in the $G C L$ were significantly higher than controls only after three weeks (approximately $80 \%$ more, Figure $4 \mathrm{G}, \mathrm{p}<0.005$ ).

\subsubsection{Retinoic Acid Receptors}

Three different subtypes of RAR have been identified: $\alpha, \beta$, and $\gamma$, which heterodimerize with RXR receptors inside the nucleus upon $\mathrm{RA}$ binding to promote transcriptional modulation of RA target genes (Chambon, 1996). In the normal adult frog retina, low immunostaining levels for all three RAR subtypes were observed in the majority of the cell bodies in the GCL, and subpopulations of cells in the INL (Figure 5A, D, and G). RARa immunoreactivity was present in the somata and nuclei of retinal cells (Figure $5 A-C$ ), whereas RAR $\beta$ and $\gamma$ immunoreactivity was mainly located peripherally, in the cytoplasm and/or membrane (Figure 5D-I).

Cutting the optic nerve of the frog caused changes in RAR immunoreactivities. The immunostaining for all three RARs appeared to increase in the retina at one week after axotomy (Figure 5B, E, and $H$ ), with RAR $\alpha$ and RAR $\beta$ reaching maximum staining levels at six weeks post nerve injury (Figure $5 \mathrm{C}$ and F). In contrast, RARY immunoreactivity seemed to be most intense at 1 week after axotomy (Figure $5 \mathrm{H})$.

Western blots of control retinal homogenates for all three RARs contained strongly-staining bands at molecular weights of approximately $52 \mathrm{kDa}$ for RARa, $51 \mathrm{kDa}$ for RAR $\beta$ and $50 \mathrm{kDa}$ for RARy, consistent with those specified for the human proteins, and with the molecular weights estimated from the amphibian sequences (Figure 6A, see Supplemental figure for uncut blots).

Western blot analysis of RAR $\alpha$ protein demonstrated a significant increase at six weeks after injury compared to control (Figure $6 \mathrm{~B}, \mathrm{p}<0.05$ ). RAR $\beta$ protein values were more than twice control values at one week after axotomy $(p<0.05)$, and higher than basal RAR $\beta$ values were sustained in retinas at three and six weeks post nerve injury (Figure 6B, $p<0.01$ ). RARy protein levels at one week after injury were almost three fold higher than in control retinas $(p<0.0001)$, and then these values were significantly decreased $(44 \%$ reduction at $3 w, p<0.0005)$ but at 6 weeks were still twice the control values (Figure 6B).

\section{3. $R A$ signaling components in the optic tectum.}


In lower vertebrates, retinal ganglion cell axons innervate predominantly the contralateral tectum, in a spatial order determined by their positions in the retina and by secreted molecular cues (Erskine and Herrera, 2007). The frog optic tectum contains 9 layers; 2, 4, 6 and 8 are cell body layers and the others are plexiform layers (Figs. 7 and 9). Layer 9 comprises seven laminae that contain retinal projections and collateral dendrites of type b tectal neurons from other layers (Potter, 1969; Scalia et al., 1968).

\subsubsection{RALDH and CYP26A1}

In control optic tectum, the majority of tectal neurons showed low to moderate immunostaining for RALDH (Figure 7A). RALDH immunostaining was also evident in ependymoglial cell-like vertical processes in layer 9 (Figure 7A). Tectal neurons showed only faint staining for CYP26A1 (Fig. 7E), with stronger immunostaining in axonal processes located in the retinorecipient layer 9 , and in layers 7 and 5 (Figure 7E). At one and three weeks after axotomy, there was a notable increase in RALDH immunostaining in all cellular layers (Fig. 7B, C), then a decrease at 6 weeks, the time when the retinal axons are reconnecting with their targets in the tectum (Fig. 7D). At this time there was also an apparent increase in CYP26A1 staining in layers 4, 6, 7 and 8 (Fig. 7H).

Western blots of RALDH protein in the tectum showed that its levels were almost 3 times higher in the optic tectum one week after axotomy compared to control animals (Figure 8B, $\mathrm{p}<0.01$ ), and these augmented levels persisted up to three weeks ( $p<0.001$ ). At 6 weeks post nerve injury, RALDH values were not significantly different from controls. CYP26A1 levels did not change significantly at one and three weeks after axotomy, but were elevated by $50 \%$ at 6 weeks (Fig. 8B, p $<0.05$ ).

\subsubsection{RARs}

In control optic tecta, the majority of tectal neurons and ependymoglial cells showed low to moderate immunostaining for RARa, RARB, and RARY (Figure 9A, E, and I, respectively). RARy immunostaining was also observed in a few processes in layer 9, 8, 7, and 5 in control tecta (Figure 9I).

A general increase in the overall staining intensity was observed for RAR $\alpha$ and RAR $\beta$ in the contralateral tecta at one week after axotomy (Figure 9B, F), which was increased at 3 weeks and persisted until 6 weeks (Fig. 9D, H). RARy immunostaining remained low up to 3 weeks after axotomy, then increased at 6 weeks, particularly in layer 8 (Fig. 9H).

Immunoblot analysis of the optic tectum confirmed that RA signaling proteins abundance changes after optic nerve trauma in the frog. RAR $\alpha$ and RAR $\beta$ were upregulated at three weeks post nerve 
injury (Figure 10, almost 2x controls for both RARa and RAR $\beta, p<0.05$ ), and their levels remained higher than control values at 6 weeks cut in contralateral tectal samples $(p<0.01$ for RAR and $p<$ 0.05 for RARß). Increased RARy levels were detected only after six weeks (Figure 10, 2x higher than control, $\mathrm{p}<0.005)$.

\section{Discussion}

Our previous studies demonstrated the presence of neurotrophic factors in the frog visual system and their changes after axotomy (Duprey-Díaz et al., 2012, 2002). Application of these factors, and the activation of their intracellular pathways, promotes the survival and axonal regeneration of axotomized RGCs (Blanco et al., 2008, 2000; Ríos-Muñoz et al., 2005; Soto et al., 2006b; Vega-Meléndez et al., 2014). All-trans retinoic acid (ATRA) is an important morphogen that controls the patterning and differentiation of neurons during development, and it has also been identified as a signaling molecule and transcriptional activator that regulates the expression of target genes, including those of growth factors and their receptors (Arrieta et al., 2005; Hernández-Pedro et al., 2008; Katsuki et al., 2009; Kurauchi et al., 2011; Qi et al., 2015; Wang and Halvorsen, 1998). Our hypothesis is that RA might also be playing a key role during optic nerve regeneration in the frog, and thus the purpose of this study was to first describe the normal distribution of the endogenous RA signaling components in the frog visual system, and then to understand how injury to the optic nerve may alter it.

\subsection{Upregulation of retinal RA signaling in the retina after optic nerve injury.}

In normal adult frog retinas, we found that all the components of RA signaling are present to some extent in or near the RGCs, namely, the synthetic enzyme RALDH2, the binding proteins CRABPI and II, all three receptor subtypes, and finally the catabolic enzyme CYP26A1 which prevents more widespread diffusion of the lipophilic molecule (Stoney et al., 2015).

These results are consistent with studies in other species: RALDH isoforms have been found predominantly in Müller cells and cone outer segments of adult human retina (Harper et al., 2015), amacrine cells in the chick retina (Fischer et al., 1999), in the ONL and processes of the NFL and IPL in the postnatal guinea pig retina (Mao et al., 2012), and in mature goldfish RGCs (Nagashima et al., 2009b). CRABPs are present in chick amacrine cells (Fischer et al., 1999), and differentiating chick RGCs (Mey et al., 2001). CRABPII is also normally found in the GCL and INL of adult mouse retinas (Lin et al., 2012). RARs have been reported in the developing mouse retina (McCaffery et al., 1999), in amacrine cells of chick retina (Fischer et al., 1999), and in the GCL and INL of adult mice retina (Lin et al., 2012). In the goldfish, CYP26A1 mRNA is also present in the INL and GCL (Nagashima et al., 2009). 
In frog RGCs, RARs were found to differ in their subcellular localization; RAR a appears to be strongly expressed in the nuclei with weaker cytoplasmic expression, whereas RAR $\beta$ and RARy were mostly cytoplasmic. A nuclear localization is clearly a prerequisite for the canonical genomic regulatory function of RARs (Bastien and Rochette-Egly, 2004), and cytoplasmic receptor isoforms are perhaps more likely to be involved in non-genomic mechanisms. In mouse hippocampal neurons, dendritic RARa is required to mediate RA's non-genomic effects on synaptic homeostasis by modulating local protein translation and AMPA receptor insertion (Aoto et al., 2008; Arendt et al., 2015; Chen et al., 2014; Maghsoodi et al., 2008). In adult human hippocampal neurons it is predominantly the RAR isoform that is cytoplasmic (Fragoso et al., 2012).

In frog retina, soon after optic nerve injury there is a large increase in RALDH (and presumably RA synthesis), some increase in the CRABPs, and a large increase in RGC RAR $\beta$ and (expression. In the longer term, as the RGC axons are regenerating, these increases continue, with the addition of later RARa expression at the time when the RGC axons are entering their target, the tectum. At no stage does CYP26A1 expression significantly change. All these observations are consistent with autocrine or paracrine retinal RA signaling playing a role in RGC survival and regeneration after axotomy

Upregulation of different components of RA signaling has also been observed in the retinas of other species after axotomy, with RALDH being the best studied. Increased RALDH mRNA expression was found in RGCs of the goldfish retina at one week after optic nerve injury (Nagashima et al., 2009b). In humans, increased RALDH mRNA expression is known to occur in the postnatal eye after inducing myopia, which corresponded to increased RA levels (Harper et al., 2015). In other regions of the nervous system, RALDH is increased also after spinal cord injury and its levels peak up to two weeks following the lesion (Mey et al., 2005), and increased RALDH2 levels have been detected in the sciatic nerve after crush (Zhelyaznik et al., 2003). Even the onset of neurodegenerative disorders such as ALS has been associated with downregulation of RALDH (Corcoran et al., 2002). In our study, the sustained increased retinal RALDH levels detected through the time points at which active optic nerve regeneration occurs suggest that RA synthesis and its regulatory actions are relevant for this process. In fact, in a study done in developing zebrafish, inhibition of RA synthesis resulted in optic nerve hypoplasia and reduced retinal axons innervating the optic tectum (Yahyavi et al., 2013).

Upregulation of CRABPI and CRABPII is known to occur during optic nerve regeneration in goldfish (Nagashima et al, 2009b), and also in the adult rat sciatic nerve after nerve crush (Zhelyaznik et al., 2003). Increased RAR expression has been reported in regenerating RGCs of adult fish (Nagashima et al., 2009b), and in the rat PNS after injury (Mey, 2006). In contrast to the frog, in the axotomized 
fish retina there are temporarily reduced levels of CYP26A1 transcripts during the period when regeneration takes place (Nagashima et al., 2009).

\subsection{Upregulation of RA signaling in the tectum after optic nerve injury.}

We also found the components of RA signaling to be present in normal adult frog tectum. Modest levels of RALDH were seen in all the nuclear layers, and of the catabolic enzyme CYP26A1 in fiber layers. In addition, all three RARs were present.

There are very few other studies regarding RA signaling in the tectum of other species, and most of these deal with embryonic development. Mey and coworkers demonstrated very low levels of RA synthesis by the embryonic chick optic tectum (Mey et al., 2001). In developing mouse brain, some RA activity (and, presumably, synthesis) is detected in the tectum, but later in development it is superseded by RA originating in the RGC axons, which also contain RALDH1 and 3 (Luo et al., 2004). There is no reported expression of CYP26 in adult tectal structures (Stoney et al., 2015), and there is only one other study to localize RARs immunochemically to the tectum, and that is in the chick (Propping et al., 2007).

The present study is the first to investigate how RA signaling changes in the tectum following optic nerve injury. We found that, after axotomy and during regrowth of axons (3 weeks), the levels of RALDH rise to almost triple control values, then fall to not significantly different from control when the axons have reached the tectum at 6 weeks. Perhaps not coincidentally, at the same time the levels of CYP26A1 increase. Axotomy does not cause an immediate increase in RAR levels but RARa and RAR $\beta$ increase after 3 weeks and RAR( only after 6 weeks, when the RGC axons are re-entering the retinorecipient layers of the tectum.

\subsection{Autocrine response to axotomy in the retina versus a paracrine response to deafferentation in the tectum.}

During development, gradients of the lipophilic RA are set up by differential localization of its synthetic and catabolic enzymes, RALDH and CYP26 respectively, leading to the conclusion that RA has a paracrine role (Stoney et al., 2015). However, in some regions of adult rat and human brain, such as the hippocampus, RALDH and CYP26 co-localize in the same neurons, suggesting an autocrine intracellular signaling system (Stoney et al., 2015).

Applying this criterion of co-localization to our results, it appears that in the frog retina RALDH and CYP26A1 are both present in RGCs, albeit with the latter located primarily in RGC axons. Thus, RA synthesized by the RGCs will not be able to diffuse far from its origins before being degraded, implying 
an autocrine role in those neurons. Axotomized frog RGCs respond soon after injury by upregulating RA synthesis, which remains elevated even as the axons begin to reach their targets. The injured RGCs also upregulate the receptors RAR $\beta$ and ( which presumably enhances the response to their own RA, and promotes axonal regrowth and perhaps neuronal survival. In other animals, RAR $\beta$ in particular is associated with promotion of axonal regeneration (Wong et al., 2006; Yip et al., 2006).

Conversely, in the tectum, there appears to be very little overlap of RALDH and CYP26A1, implying a paracrine role for RA. However, the range of diffusion would be relatively limited; for example, RA synthesized by neurons of layer 6 would be prevented from accessing those of layer 8 by the degradative enzyme in processes of layer 7. The tectal neurons show a delayed response to deafferentation by increasing RA synthesis and also the production of RARs. RA signaling is known to be induced by synaptic inactivity and has an important role in synaptic homeostasis via the nongenomic direct activation of protein synthesis by RARa, and the insertion of AMPA receptors (Arendt et al., 2015; Chen et al., 2014). This would be in accordance with the rapid increase in RALDH that we observe after optic nerve injury, however does not account for the much slower rise in RAR expression. Indeed, RAR( does not increase until the time when retinal axons are re-entering the tectum - whether this implies a causal connection remains to be determined. It has recently been shown that unliganded RARs can act as transcriptional repressors (Janesick et al., 2014). Thus at this late stage in regeneration of the frog visual system, when tectal RA synthesis is decreased, CYP26A1 activity is increased, yet RAR levels remain high, the excess unbound RARs could perhaps be acting to repress gene transcription.

\subsection{Conclusions.}

Our working hypothesis for this study was that RA plays an important role in the response of the frog visual system to optic nerve injury. We find that all the components of RA signaling (the synthetic and degradative enzymes, binding proteins, and receptors) are indeed increased in both retina and optic tectum, suggesting that it may be involved in both the survival of RGCs and their regenerative abilities. In the future we will use pharmacological tools to test the effects of RA on RGC survival and regeneration.

\section{Acknowledgements.}

REB is supported by NIH grant GM116692, JMB by NIH grant NSS081726. The Institute confocal microscope was funded by NSF DBI 0115825, DoD 52680-RT-ISP and NIMHD G12 MD007600 (RCMI). 


\section{Figure Legends}

Figure 1. Retrograde TDA labeling shows that RA signaling components are present in RGCs. Immunostaining was carried out against RALDH, RARa, RAR $\beta$, and RARy in frozen sections of retinas from animals retrogradely labeled 2 days earlier with TDA. Antibody staining is shown in the left column (green), TDA labeling in the center column (red) and the merged images are shown in the right column. In A, the inner plexiform layer (IPL), ganglion cell layer (GCL) and nerve fiber layer (NFL) are indicated. A-C. RALDH immunoreactivity is present in RGC cell bodies and axons. D-F. RARa immunoreactivity is present in RGC cell bodies and axons. G-I. RAR $\beta$ immunoreactivity is present in the periphery of RGCs and in their axons. Immunostaining is also present in the IPL. J-L. RARy immunoreactivity is present in the periphery of RGCs but not in their axons. Scale bar in A: $50 \mu \mathrm{m}$.

Figure 2. Changes in the immunolocalization of RA synthetic and degradative enzymes in the retina after axotomy. Immunostaining was carried out against RALDH and CYP26A1 in frozen sections of retinas from control animals (left column) and animals at 1 week (center column) and 6 weeks (right column) after the optic nerve was cut. In $A$, the inner nuclear layer (INL), inner plexiform layer (IPL), ganglion cell layer (GCL) and nerve fiber layer (NFL) are indicated. A. In uncut control frog retinal sections, low levels of RALDH immunoreactivity are present in RGC cell bodies (GCL) and axons (NFL), in some cells at the inner margins of the INL, and also in processes of the OPL. B. One week after axotomy, RALDH staining has increased in intensity, particularly in RGCs of the GCL and their axons, and in the cells in the INL. C. Six weeks after axotomy, RALDH staining remains at high levels in RGCs and their axons. D. In uncut control frog retinal sections, low levels of CYP26A1 immunoreactivity are present throughout the retina, with stronger staining mainly in RGC axons (NFL), and also in processes of the OPL. E, F. One week and six weeks after axotomy, there are no obvious changes in the pattern of CYP26A1 staining. Scale bar in A: $50 \mu \mathrm{m}$.

Figure 3. The RA synthetic enzyme RALDH increases in the retina after axotomy. A. Representative Western blots of RALDH, CYP26A1 and the loading control GAPDH from extracts of control animals (C), and animals at 1 week, 3 weeks and 6 weeks after axotomy. Approximate molecular weight in $\mathrm{kDa}$ is indicated. B. Quantification of Western blots, standardized to control values. RALDH significantly increases at 1 week after axotomy, and continues to increase at 3 weeks. By 6 weeks its levels have declined, but remain significantly higher than control values. In contrast, the levels of CYP26A1 show no significant change compared to controls. One-way ANOVA followed by post-hoc Tukey tests: * $p<0.05,{ }^{* *} p<0.01,{ }^{* * *} p<0.001$.

Figure 4. Changes in CRABPs in the retina after axotomy. Immunostaining was carried out against CRABPI and CRABPII in frozen sections of retinas from control animals (left column) and animals at 1 
week (center column) and 6 weeks (right column) after the optic nerve was cut. In A, the outer plexiform layer (OPL), inner nuclear layer (INL), inner plexiform layer (IPL), ganglion cell layer (GCL) and nerve fiber layer (NFL) are indicated. A. In uncut control frog retinal sections, low levels of CRABPI immunoreactivity are present in the GCL and the INL. Some staining is present in Müller cell processes (asterisks). B. One week after axotomy, CRABPI staining has increased in intensity in RGCs of the GCL, but more so in cells of the INL and processes in the OPL. C. Six weeks after axotomy, CRABPI staining remains elevated. D. In uncut control frog retinal sections, low levels of CRABPII immunoreactivity are present in the GCL and moderate staining in the INL. E, F. One week and six weeks after axotomy, there are increased levels of CRABPII staining, particularly in the INL. Scale bar in A: $50 \mu \mathrm{m}$. G. Quantification of CRABP immunostaining intensity in the GCL, at different times after axotomy. There is a significant increase in CRABPI (but not CRABPII) staining intensity at 1 week after axotomy compared to controls. At 3 weeks the staining for both CRABPs is significantly elevated, as is the case at 6 weeks. One-way ANOVA followed by post-hoc Tukey tests: * $p<0.05$, ** $p<0.01,{ }^{* * *} p<0.001$.

\section{Figure 5. Changes in the immunolocalization of RA receptors in the retina after axotomy.} Immunostaining was carried out against RAR $\alpha, R A R \beta$, and RARy in frozen sections of retinas from control animals (left column) and animals at 1 week (center column) and 6 weeks (right column) after the optic nerve was cut. In A, the inner nuclear layer (INL), inner plexiform layer (IPL), ganglion cell layer (GCL) and nerve fiber layer (NFL) are indicated. A. In uncut control frog retinal sections, low levels of RARa immunoreactivity are present in the GCL and the INL. B. One week after axotomy, RARa staining has increased in intensity, particularly in the cell bodies of RGCs of the GCL and their axons, and in the cells in the INL. C. Six weeks after axotomy, RARa staining is further increased in RGCs and their axons. D. In uncut control frog retinal sections, low levels of RAR $\beta$ immunoreactivity are present in the periphery of neurons in the GCL and INL. E, F. One week and six weeks after axotomy, there are increased levels of RAR $\beta$ staining, particularly in the cytoplasm of RGCs. G. In control frog retinal sections, low levels of RARy immunoreactivity are present in the periphery of neurons in the GCL and INL. H, I. One week and six weeks after axotomy, there are increased levels of RARy staining, particularly in the cytoplasm of RGCs. Scale bar in A: $50 \mu \mathrm{m}$.

Figure 6. The RARs increase in the retina after axotomy. A. Representative Western blots of RAR $\alpha$, RAR $\beta$, and RARy and the loading control GAPDH from extracts of control animals (C), and animals at 1 week, 3 weeks and 6 weeks after axotomy. Approximate molecular weight in kDa is indicated. B. Quantification of Western blots, normalized to control values. RARa is significantly increased compared to control values only at 6 weeks after axotomy. RAR $\beta$ is significantly increased at 1 week, 3 weeks and 6 weeks after axotomy compared to controls. RARy levels almost triple 1 
week after axotomy, then decreases somewhat by 3 weeks but remains at twice control levels at 6 weeks. One-way ANOVA followed by post-hoc Tukey tests: * $p<0.05,{ }^{* *} p<0.01,{ }^{* * *} p<0.001$.

Figure 7. Changes in the immunolocalization of RALDH and CYP26A1 in the tectum after axotomy. Immunostaining was carried out against RALDH and CYP26A1 in frozen sections of tecta from control animals, animals at 1 week, 3 weeks, and 6 weeks after the optic nerve was cut. In A, different tectal layers are enumerated. A. In control frog retinal sections, low levels of RALDHI immunoreactivity are present in cellular layers. B. One week after axotomy, RALDH staining has increased in intensity. C. Three weeks after axotomy, RALDH staining remains elevated. D. Six weeks after axotomy, RALDH staining is diminished. E-F. In control frog tectal sections, and at 1 and 3 weeks after axotomy, low levels of CYP26A1 immunoreactivity are present in cell processes. H. At 6 weeks the tectal CYP26A1 immunostaining is more intense. Scale bar in A: $100 \mu \mathrm{m}$.

Figure 8. RALDH and CYP26A1 increase in the tectum after axotomy. A. Representative Western blots of RALDH, CYP26A1, and the loading control GAPDH from extracts of control animals (C), and animals at 1 week, 3 weeks and 6 weeks after axotomy. Approximate molecular weight in kDa is indicated. B. Quantification of Western blots, normalized to control values. RALDH is significantly increased compared to control values at 1,3 and 6 weeks after axotomy. CYP26A1 levels are significantly greater than controls only at 6 weeks after axotomy. One-way ANOVA followed by posthoc Tukey tests: * $p<0.05,{ }^{* *} p<0.01,{ }^{* * *} p<0.001$.

Figure 9. Changes in the immunolocalization of RARs in the tectum after axotomy. Immunostaining was carried out against RAR $\alpha, R A R \beta$, and RARY in frozen sections of tecta from control animals, animals at 1 week, 3 weeks, and 6 weeks after the optic nerve was cut. In A, different tectal layers are enumerated. A. In control frog retinal sections, low levels of RARa immunoreactivity are present in cellular layers. B-D. At 1-6 weeks after axotomy, RARa staining is increased in intensity. E. In control frog tectal sections, there is weak RAR $\beta$ immunostaining. F-H. At 1-6 weeks after axotomy, RARß staining is increased in intensity in cellular layers. I-K. In control tecta, and at 1-3 weeks after axotomy, RARy immunostaining is of low intensity in cell bodies, and some staining is present in axonal processes. L. At 6 weeks RARy immunostaining is more intense, particularly in layer 8. Scale bar in A: $100 \mu \mathrm{m}$.

Figure 10. RARs increase in the tectum after axotomy. A. Representative Western blots of RAR RAR $\beta$, RARy, and the loading control GAPDH from extracts of control animals (C), and animals at 1 week, 3 weeks and 6 weeks after axotomy. Approximate molecular weight in kDa is indicated. B. Quantification of Western blots, normalized to control values. RARa is significantly increased compared to control values at 3 and 6 weeks after axotomy. RAR $\beta$ is significantly increased at 3 
weeks and 6 weeks after axotomy. RARy levels are significantly greater than controls only at 6 weeks after axotomy. One-way ANOVA followed by post-hoc Tukey tests: ${ }^{*} p<0.05,{ }^{* *} p<0.01,{ }^{* * *} p<0.001$. 


\section{References}

Aoto, J., Nam, C.I., Poon, M.M., Ting, P., Chen, L., 2008. Synaptic signaling by all-trans retinoic acid in homeostatic synaptic plasticity. Neuron 60, 308-20. doi:10.1016/j.neuron.2008.08.012

Arendt, K.L., Zhang, Z., Ganesan, S., Hintze, M., Shin, M.M., Tang, Y., Cho, A., Graef, I.A., Chen, L., 2015. Calcineurin mediates homeostatic synaptic plasticity by regulating retinoic acid synthesis. Proc. Natl. Acad. Sci. U. S. A. 112, E5744-52. doi:10.1073/pnas.1510239112

Arrieta, O., García-Navarrete, R., Zúñiga, S., Ordóñez, G., Ortiz, A., Palencia, G., Morales-Espinosa, D., Hernández-Pedro, N., Sotelo, J., 2005. Retinoic acid increases tissue and plasma contents of nerve growth factor and prevents neuropathy in diabetic mice. Eur. J. Clin. Invest. 35, 201-7. doi:10.1111/j.1365-2362.2005.01467.x

Bastien, J., Rochette-Egly, C., 2004. Nuclear retinoid receptors and the transcription of retinoid-target genes. Gene 328, 1-16. doi:10.1016/j.gene.2003.12.005

Blanco, R.E., Lopez-Roca, A., Soto, J., Blagburn, J.M., 2000. Basic fibroblast growth factor applied to the optic nerve after injury increases long-term cell survival in the frog retina. J Comp Neurol 423, $646-658$.

Blanco, R.E., Soto, I., Duprey-Díaz, M., Blagburn, J.M., 2008. Up-regulation of brain-derived neurotrophic factor by application of fibroblast growth factor-2 to the cut optic nerve is important for long-term survival of retinal ganglion cells. J. Neurosci. Res. 86, 3382-92. doi:10.1002/jnr.21793

Burger, P.E., Gupta, R., Xiong, X., Ontiveros, C.S., Salm, S.N., Moscatelli, D., Wilson, E.L., 2009. High aldehyde dehydrogenase activity: a novel functional marker of murine prostate stem/progenitor cells. Stem Cells 27, 2220-8. doi:10.1002/stem.135

Chambon, P., 1996. A decade of molecular biology of retinoic acid receptors. FASEB J. 10, 940-54.

Chen, L., Lau, A.G., Sarti, F., 2014. Synaptic retinoic acid signaling and homeostatic synaptic plasticity. Neuropharmacology 78, 3-12. doi:10.1016/j.neuropharm.2012.12.004

Corcoran, J.P.T., So, P.L., Maden, M., 2004. Disruption of the retinoid signalling pathway causes a deposition of amyloid beta in the adult rat brain. Eur. J. Neurosci. 20, 896-902.

doi:10.1111/j.1460-9568.2004.03563.x

Dong, D., Ruuska, S.E., Levinthal, D.J., Noy, N., 1999. Distinct roles for cellular retinoic acid-binding proteins I and II in regulating signaling by retinoic acid. J. Biol. Chem. 274, 23695-8.

Duprey-Díaz, M. V, Blagburn, J.M., Blanco, R.E., 2012. Changes in fibroblast growth factor-2 and FGF receptors in the frog visual system during optic nerve regeneration. J. Chem. Neuroanat. 46, 3544. doi:10.1016/j.jchemneu.2012.08.003

Duprey-Díaz, M. V, Soto, I., Blagburn, J.M., Blanco, R.E., Duprey-Diaz, M. V, Soto, I., Blagburn, J.M., Blanco, R.E., 2002. Changes in brain-derived neurotrophic factor and trkB receptor in the adult Rana pipiens retina and optic tectum after optic nerve injury. J. Comp. Neurol. 454, 456-69. doi:10.1002/cne. 10451 
Erskine, L., Herrera, E., 2007. The retinal ganglion cell axon's journey: insights into molecular mechanisms of axon guidance. Dev. Biol. 308, 1-14. doi:10.1016/j.ydbio.2007.05.013

Fragoso, Y.D., Shearer, K.D., Sementilli, A., de Carvalho, L.V., McCaffery, P.J., 2012. High expression of retinoic acid receptors and synthetic enzymes in the human hippocampus. Brain Struct. Funct. 217, 473-483. doi:10.1007/s00429-011-0359-0

Goodman, T., Crandall, J.E., Nanescu, S.E., Quadro, L., Shearer, K., Ross, A., McCaffery, P., 2012. Patterning of retinoic acid signaling and cell proliferation in the hippocampus. Hippocampus 22, 2171-83. doi:10.1002/hipo.22037

Hernández-Pedro, N., Ordóñez, G., Ortiz-Plata, A., Palencia-Hernández, G., García-Ulloa, A.C., Flores-Estrada, D., Sotelo, J., Arrieta, O., 2008. All-trans retinoic acid induces nerve regeneration and increases serum and nerve contents of neural growth factor in experimental diabetic neuropathy. Transl. Res. 152, 31-7. doi:10.1016/j.trsl.2008.05.007

Janesick, A., Nguyen, T.T.L., Aisaki, K., Igarashi, K., Kitajima, S., Chandraratna, R.A.S., Kanno, J., Blumberg, B., 2014. Active repression by RARy signaling is required for vertebrate axial elongation. Development 141, 2260-70. doi:10.1242/dev.103705

Jokic, N., Ling, Y.Y., Ward, R.E., Michael-Titus, A.T., Priestley, J. V, Malaspina, A., 2007. Retinoid receptors in chronic degeneration of the spinal cord: observations in a rat model of amyotrophic lateral sclerosis. J. Neurochem. 103, 1821-33. doi:10.1111/j.1471-4159.2007.04893.x

Katsuki, H., Kurimoto, E., Takemori, S., Kurauchi, Y., Hisatsune, A., Isohama, Y., Izumi, Y., Kume, T., Shudo, K., Akaike, A., 2009. Retinoic acid receptor stimulation protects midbrain dopaminergic neurons from inflammatory degeneration via BDNF-mediated signaling. J. Neurochem. 110, 70718. doi:10.1111/j.1471-4159.2009.06171.x

Kawahara, K., Suenobu, M., Ohtsuka, H., Kuniyasu, A., Sugimoto, Y., Nakagomi, M., Fukasawa, H., Shudo, K., Nakayama, H., 2014. Cooperative therapeutic action of retinoic acid receptor and retinoid $x$ receptor agonists in a mouse model of Alzheimer's disease. J. Alzheimers. Dis. 42, 587-605. doi:10.3233/JAD-132720

Kolarcik, C.L., Bowser, R., 2012. Retinoid signaling alterations in amyotrophic lateral sclerosis. Am. J. Neurodegener. Dis. 1, 130-45.

Koriyama, Y., Sugitani, K., Ogai, K., Kato, S., 2014. Neuritogenic activity of trichostatin A in adult rat retinal ganglion cells through acetylation of histone $\mathrm{H} 3$ lysine 9 and RAR $\beta$ induction. J. Pharmacol. Sci. 124, 112-6.

Kurauchi, Y., Hisatsune, A., Isohama, Y., Sawa, T., Akaike, T., Shudo, K., Katsuki, H., 2011. Midbrain dopaminergic neurons utilize nitric oxide/cyclic GMP signaling to recruit ERK that links retinoic acid receptor stimulation to up-regulation of BDNF. J. Neurochem. 116, 323-33.

doi:10.1111/j.1471-4159.2010.06916.x

Luo, T., Wagner, E., Grün, F., Dräger, U.C., 2004. Retinoic acid signaling in the brain marks formation of optic projections, maturation of the dorsal telencephalon, and function of limbic sites. J. Comp. Neurol. 470, 297-316. doi:10.1002/cne.20013 
Lupo, G., Liu, Y., Qiu, R., Chandraratna, R.A.S., Barsacchi, G., He, R.-Q., Harris, W.A., 2005. Dorsoventral patterning of the Xenopus eye: a collaboration of Retinoid, Hedgehog and FGF receptor signaling. Development 132, 1737-48. doi:10.1242/dev.01726

Lutz, J.D., Dixit, V., Yeung, C.K., Dickmann, L.J., Zelter, A., Thatcher, J.E., Nelson, W.L., Isoherranen, N., 2009. Expression and functional characterization of cytochrome P450 26A1, a retinoic acid hydroxylase. Biochem. Pharmacol. 77, 258-68. doi:10.1016/j.bcp.2008.10.012

Maden, M., 2007. Retinoic acid in the development, regeneration and maintenance of the nervous system. Nat. Rev. Neurosci. 8, 755-65. doi:10.1038/nrn2212

Maghsoodi, B., Poon, M.M., Nam, C.I., Aoto, J., Ting, P., Chen, L., 2008. Retinoic acid regulates RAR -mediated control of translation in dendritic RNA granules during homeostatic synaptic plasticity. Proc. Natl. Acad. Sci. 105, 16015-16020. doi:10.1073/pnas.0804801105

McCaffery, P., Dräger, U.C., 1994. High levels of a retinoic acid-generating dehydrogenase in the meso-telencephalic dopamine system. Proc. Natl. Acad. Sci. U. S. A. 91, 7772-6.

McCaffery, P., Lee, M.O., Wagner, M.A., Sladek, N.E., Dräger, U.C., 1992. Asymmetrical retinoic acid synthesis in the dorsoventral axis of the retina. Development 115, 371-82.

McCaffery, P., Wagner, E., O’Neil, J., Petkovich, M., Dräger, U.C., 1999. Dorsal and ventral rentinoic territories defined by retinoic acid synthesis, break-down and nuclear receptor expression. Mech. Dev. 85, 203-14.

McCaffery, P., Zhang, J., Crandall, J.E., 2006. Retinoic acid signaling and function in the adult hippocampus. J. Neurobiol. 66, 780-91. doi:10.1002/neu.20237

Mey, J., J Morassutti, D., Brook, G., Liu, R.-H., Zhang, Y.-P., Koopmans, G., McCaffery, P., 2005. Retinoic acid synthesis by a population of NG2-positive cells in the injured spinal cord. Eur. J. Neurosci. 21, 1555-68. doi:10.1111/j.1460-9568.2005.03928.x

Nagashima, M., Sakurai, H., Mawatari, K., Koriyama, Y., Matsukawa, T., Kato, S., 2009. Involvement of retinoic acid signaling in goldfish optic nerve regeneration. Neurochem. Int. 54, 229-36. doi:10.1016/j.neuint.2008.11.007

Napoli, J.L., 2012. Physiological insights into all-trans-retinoic acid biosynthesis. Biochim. Biophys. Acta 1821, 152-67. doi:10.1016/j.bbalip.2011.05.004

Pisitkun, T., Hoffert, J.D., Saeed, F., Knepper, M.A., 2012. NHLBI-AbDesigner: an online tool for design of peptide-directed antibodies. Am. J. Physiol. Cell Physiol. 302, C154-64. doi:10.1152/ajpcell.00325.2011

Potter, H.D., 1969. Structural characteristics of cell and fiber populations in the optic tectum of the frog (Rana catesbeiana). J Comp Neurol 136, 203-231.

Propping, C., Mönig, B., Luksch, H., Mey, J., 2007. Distribution of the cellular retinoic acid binding protein CRABP-I in the developing chick optic tectum. Brain Res. 1168, 21-31. doi:10.1016/j.brainres.2007.06.089 
Qi, X.-R., Zhao, J., Liu, J., Fang, H., Swaab, D.F., Zhou, J.-N., 2015. Abnormal retinoid and TrkB signaling in the prefrontal cortex in mood disorders. Cereb. Cortex 25, 75-83. doi:10.1093/cercor/bht203

Ransom, J., Morgan, P.J., McCaffery, P.J., Stoney, P.N., 2014. The rhythm of retinoids in the brain. J. Neurochem. 129, 366-76. doi:10.1111/jnc.12620

Ríos-Muñoz, W., Soto, I., Duprey-Díaz, M. V, Blagburn, J.M., Blanco, R.E., 2005. Fibroblast growth factor 2 applied to the optic nerve after axotomy increases Bcl-2 and decreases Bax in ganglion cells by activating the ERK signaling pathway. J. Neurochem. 93, 1422-1433.

Scalia, C.R., Gendusa, R., Basciu, M., Riva, L., Tusa, L., Musarò, A., Veronese, S., Formenti, A., D’Angelo, D., Ronzio, A.G., Cattoretti, G., Bolognesi, M.M., 2015. Epitope recognition in the human-pig comparison model on fixed and embedded material. J. Histochem. Cytochem. 63, 805-22. doi:10.1369/0022155415597738

Scalia, F., Knapp, H., Halpern, M., Riss, W., 1968. New observations on the retinal projection in the frog tectum. J. Anat. 114, 261-269.

Shearer, K.D., Stoney, P.N., Morgan, P.J., McCaffery, P.J., 2012. A vitamin for the brain. Trends Neurosci. 35, 733-41. doi:10.1016/j.tins.2012.08.005

Soto, I., López-Roca, T., Blagburn, J.M., Blanco, R.E., 2006a. Changes in nNOS and NADPH diaphorase in frog retina and tectum after axotomy and FGF-2 application. Brain Res. 1103, 6575. doi:10.1016/j.brainres.2006.05.062

Soto, I., Marie, B., Baro, D.J., Blanco, R.E., 2003. FGF-2 modulates expression and distribution of GAP-43 in frog retinal ganglion cells after optic nerve injury. J Neurosci Res 73, 507-517.

Soto, I., Rosenthal, J.J., Blagburn, J.M., Blanco, R.E., 2006b. Fibroblast growth factor 2 applied to the optic nerve after axotomy up-regulates BDNF and TrkB in ganglion cells by activating the ERK and PKA signaling pathways. J Neurochem 96, 82-96.

Stoney, P.N., Fragoso, Y.D., Saeed, R.B., Ashton, A., Goodman, T., Simons, C., Gomaa, M.S., Sementilli, A., Sementilli, L., Ross, A.W., Morgan, P.J., McCaffery, P.J., 2015. Expression of the retinoic acid catabolic enzyme CYP26B1 in the human brain to maintain signaling homeostasis. Brain Struct. Funct. doi:10.1007/s00429-015-1102-z

Thomas, A.G., Henry, J.J., 2014. Retinoic acid regulation by CYP26 in vertebrate lens regeneration. Dev. Biol. 386, 291-301. doi:10.1016/j.ydbio.2013.12.036

Thompson Haskell, G., Maynard, T.M., Shatzmiller, R.A., Lamantia, A.-S., 2002. Retinoic acid signaling at sites of plasticity in the mature central nervous system. J. Comp. Neurol. 452, 22841. doi:10.1002/cne.10369

Trasino, S.E., Benoit, Y.D., Gudas, L.J., 2015. Vitamin A deficiency causes hyperglycemia and loss of pancreatic $\beta$-cell mass. J. Biol. Chem. 290, 1456-73. doi:10.1074/jbc.M114.616763

Vega-Meléndez, G.S., Blagburn, J.M., Blanco, R.E., 2014. Ciliary neurotrophic factor and fibroblast growth factor increase the speed and number of regenerating axons after optic nerve injury in adult Rana pipiens. J Neurosci Res 92, 13-23. doi:10.1002/jnr.23303 
Wang, X., Halvorsen, S.W., 1998. Retinoic acid up-regulates ciliary neurotrophic factor receptors in cultured chick neurons and cardiomyocytes. Neurosci. Lett. 240, 9-12.

White, J.A., Guo, Y.D., Baetz, K., Beckett-Jones, B., Bonasoro, J., Hsu, K.E., Dilworth, F.J., Jones, G., Petkovich, M., 1996. Identification of the retinoic acid-inducible all-trans-retinoic acid 4hydroxylase. J. Biol. Chem. 271, 29922-7.

Wong, L.-F., Yip, P.K., Battaglia, A., Grist, J., Corcoran, J., Maden, M., Azzouz, M., Kingsman, S.M., Kingsman, A.J., Mazarakis, N.D., McMahon, S.B., 2006. Retinoic acid receptor beta2 promotes functional regeneration of sensory axons in the spinal cord. Nat. Neurosci. 9, 243-50. doi:10.1038/nn1622

Yip, P.K., Wong, L.-F., Pattinson, D., Battaglia, A., Grist, J., Bradbury, E.J., Maden, M., McMahon, S.B., Mazarakis, N.D., 2006. Lentiviral vector expressing retinoic acid receptor beta2 promotes recovery of function after corticospinal tract injury in the adult rat spinal cord. Hum. Mol. Genet. 15, 3107-18. doi:10.1093/hmg/ddl251

Zhelyaznik, N., Mey, J., 2006. Regulation of retinoic acid receptors alpha, beta and retinoid X receptor alpha after sciatic nerve injury. Neuroscience 141, 1761-74.

doi:10.1016/j.neuroscience.2006.05.021

Zhelyaznik, N., Schrage, K., McCaffery, P., Mey, J., 2003. Activation of retinoic acid signalling after sciatic nerve injury: up-regulation of cellular retinoid binding proteins. Eur. J. Neurosci. 18, 103340. 
RALDH IPL

GCL $-S$ or a d P NFL

B

C

cosa

D

E

F

$\operatorname{RAR} \alpha$

RAR $\beta$
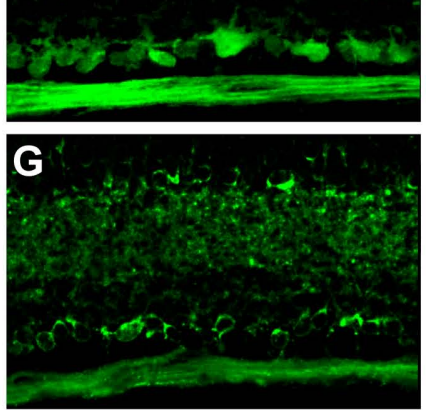

$\mathbf{R A R} \gamma$

J

30

29.

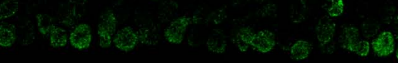

H
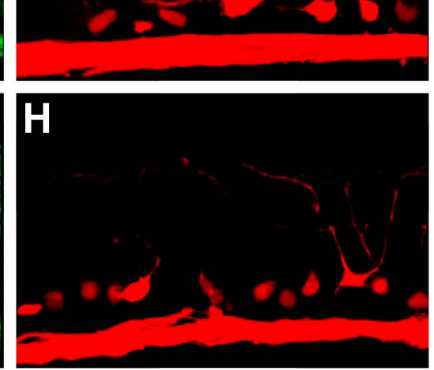

K

L
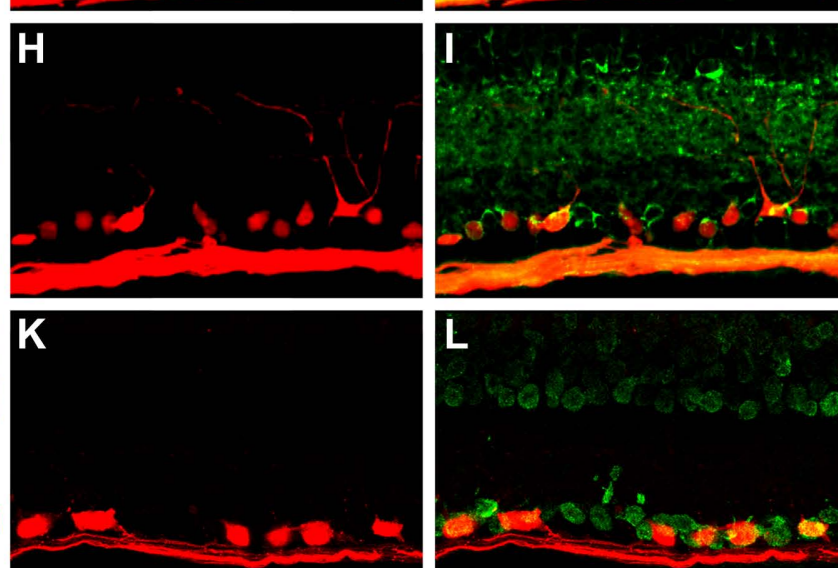


\section{Control}

\section{1w cut}

$6 w$ cut

\section{RALDH}
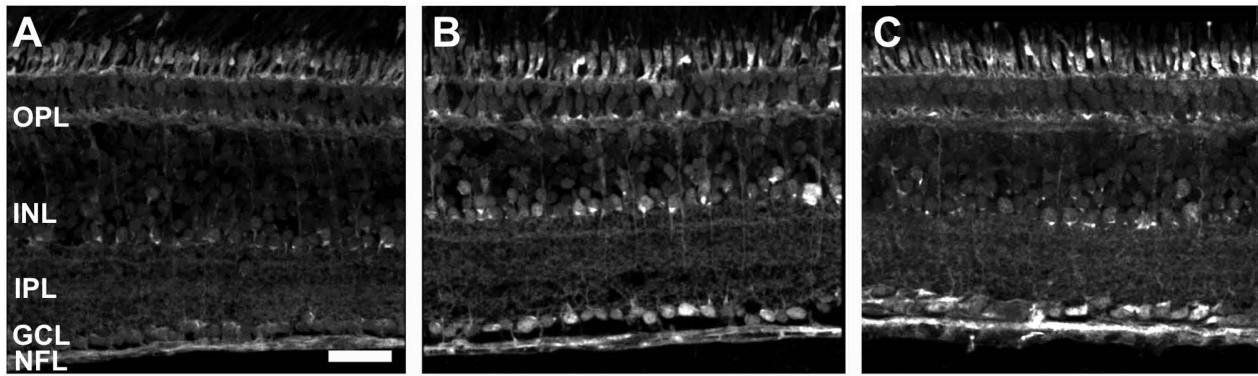

CYP26A1

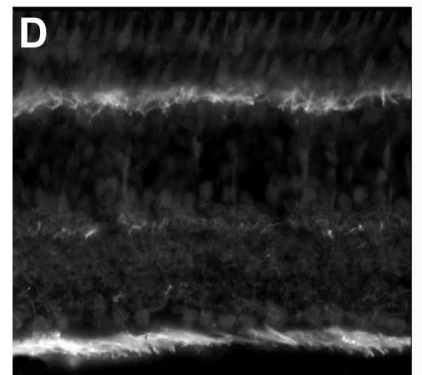

F

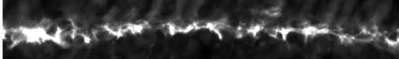

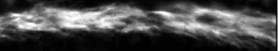

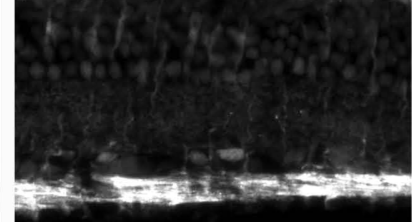




\section{1w 3w $6 w$}

RALDH

CYP26A1

GAPDH
$53 \mathrm{kDa}$

$49 \mathrm{kDa}$

$37 \mathrm{kDa}$

B

$\square$ RALDH

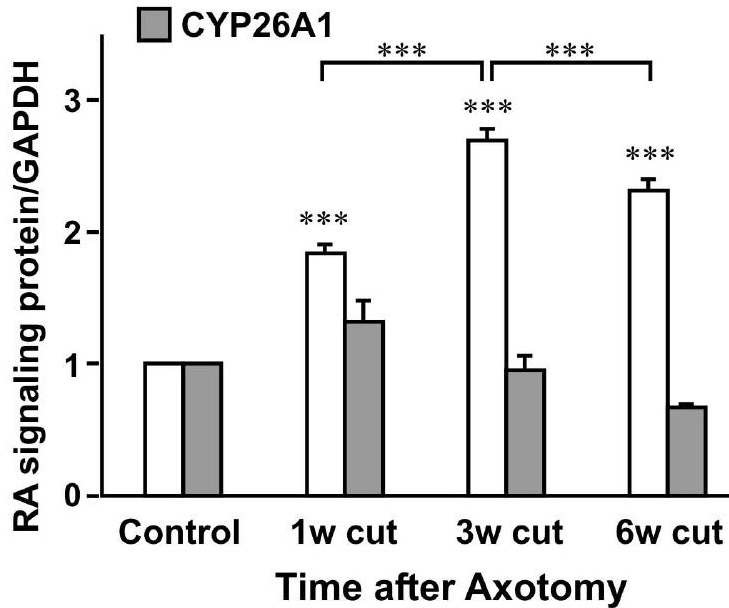


Control

1w cut

6w cut

CRABPI

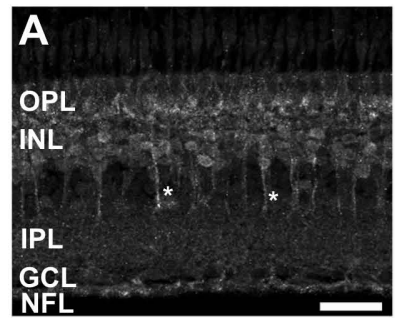

CRABPII

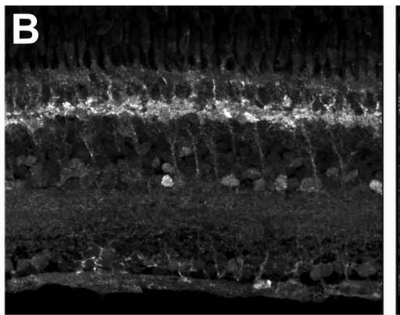

C

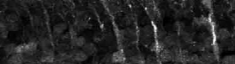

D
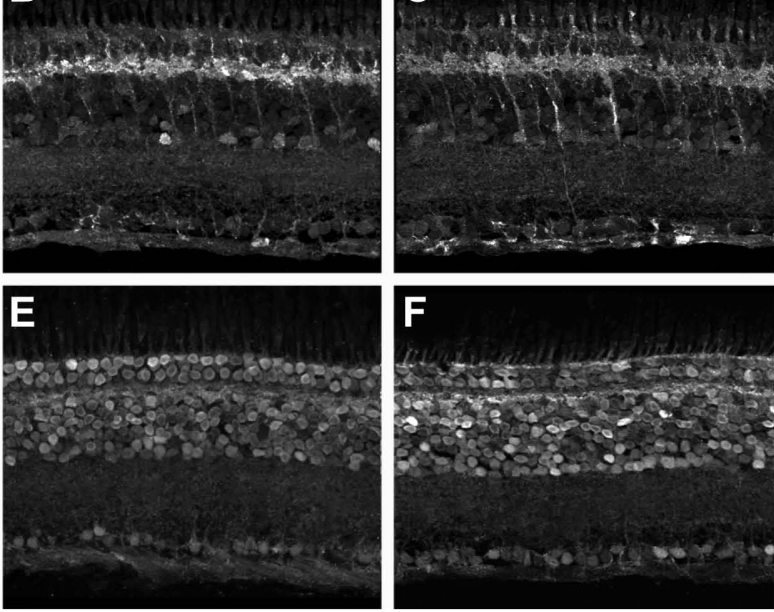

G

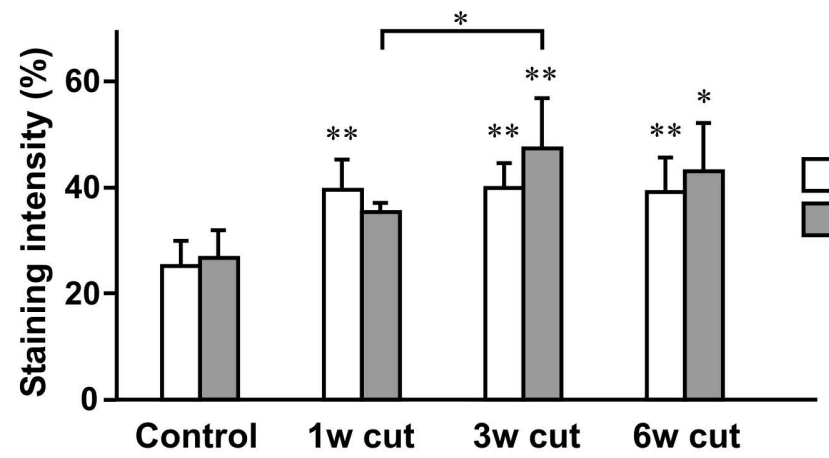

$\square$ CRABPI $\square$ CRABPII

Time after Axotomy 
Control

$\operatorname{RAR} \alpha$

$\operatorname{RAR} \beta$

$\mathbf{R A R} \gamma$

\section{D}

1w cut

6w cut
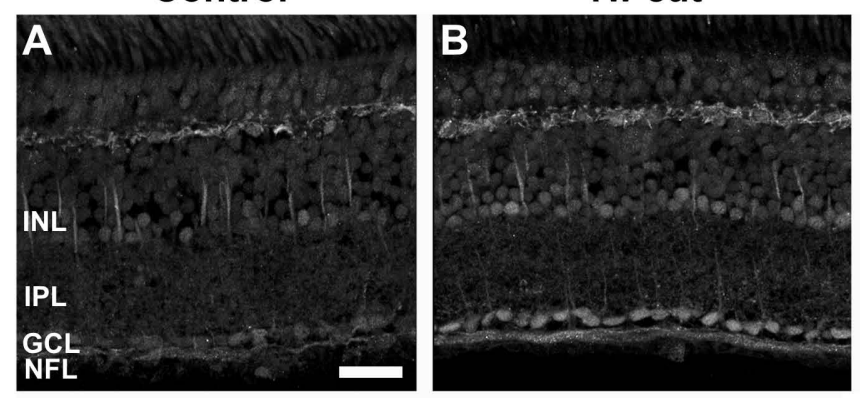

\section{C}

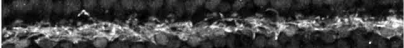

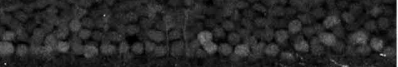

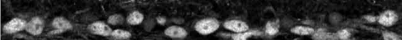
$-2-2-2+3$

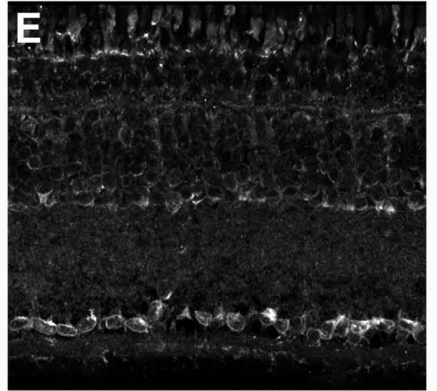

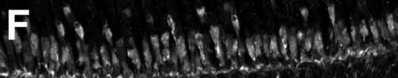
Dow.

weth $4 x+y)+40$

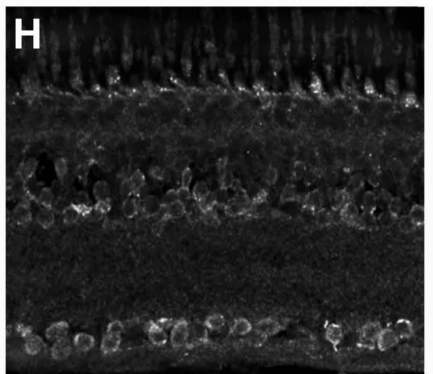

G 
RAR $\alpha$ RAR $\beta$ RAR $\gamma$

\section{GAPDH}

$52 \mathrm{kDa}$ $51 \mathrm{kDa}$ $50 \mathrm{kDa}$ $37 \mathrm{kDa}$

B

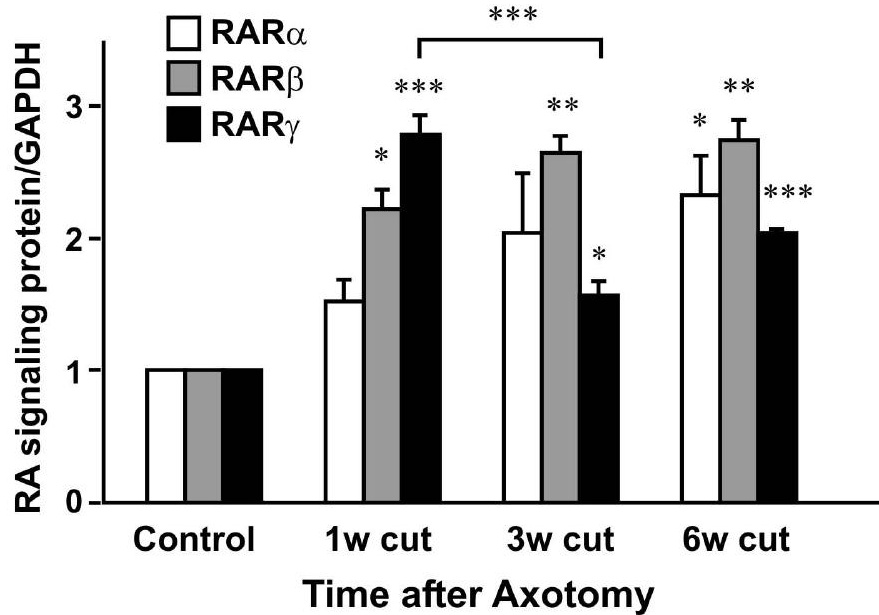




\section{RALDH}

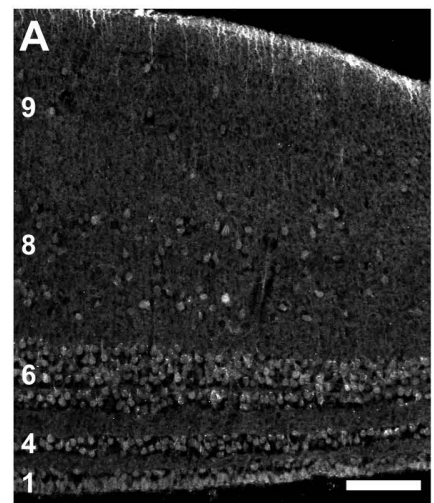

B

Therting

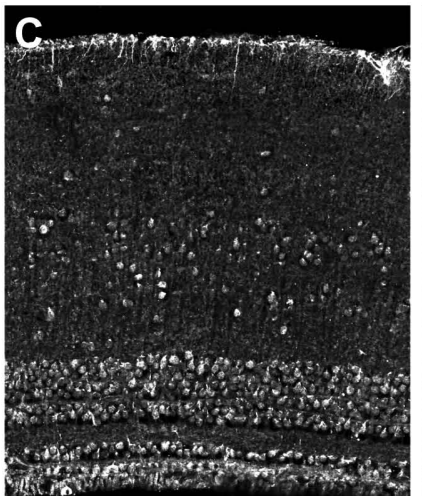

D.

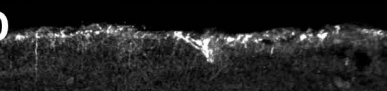

\section{CYP26A1}
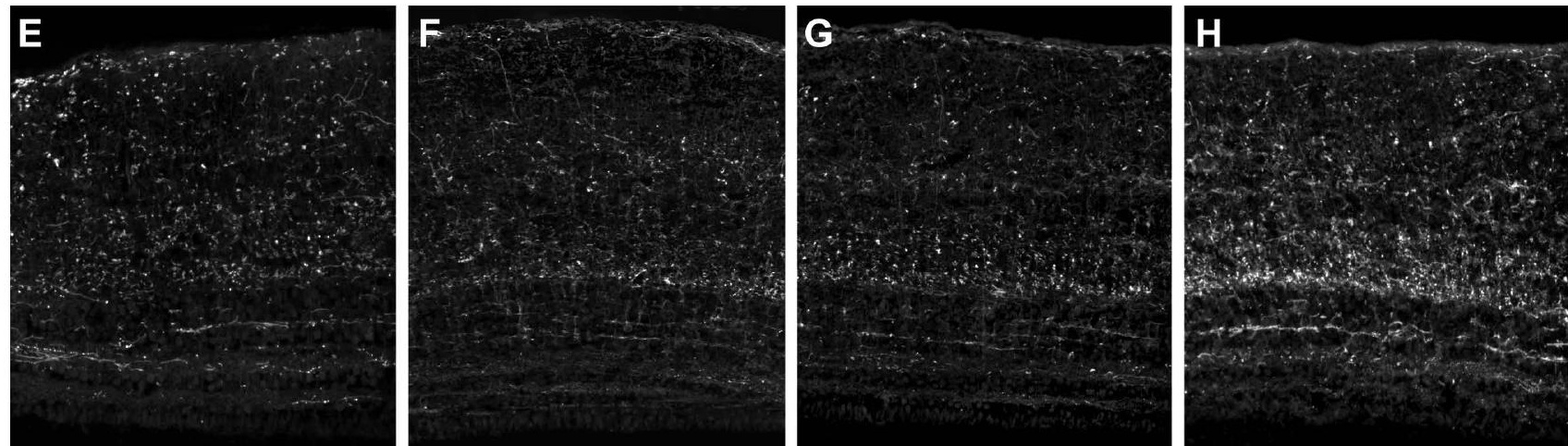


\section{1w 3w $6 w$}

RALDH

CYP26A1

GAPDH
$53 \mathrm{kDa}$

$49 \mathrm{kDa}$

$37 \mathrm{kDa}$

B

$\square$ RALDH

$\square$ CYP26A1

***

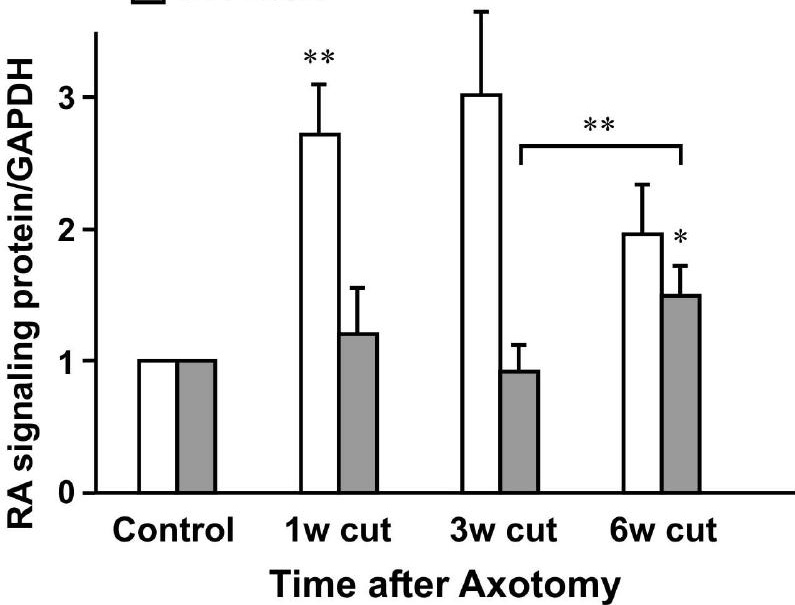




\section{Control}

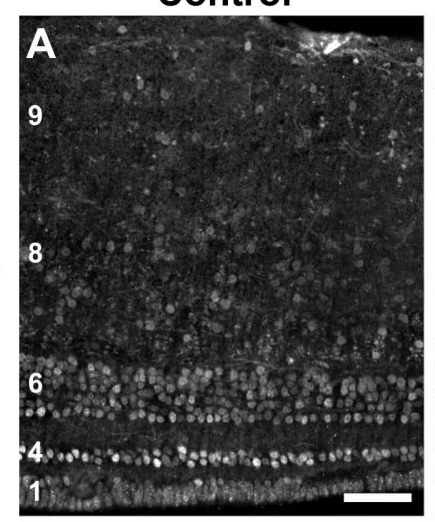

$\operatorname{RAR} \alpha$

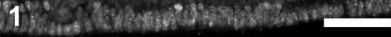

$\operatorname{RAR} \beta$

$\mathbf{R A R} \gamma$

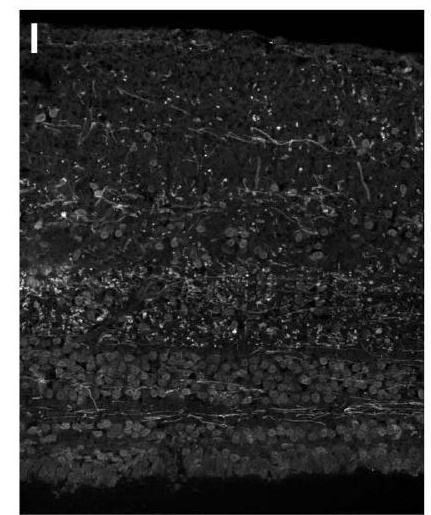

E

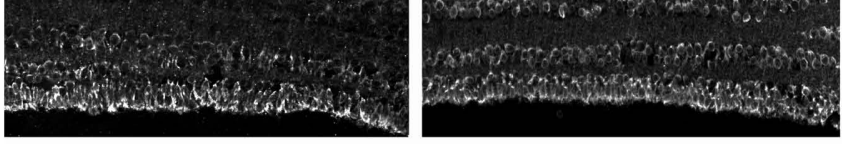

B

-7.

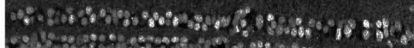

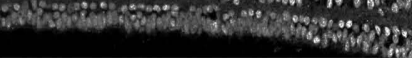

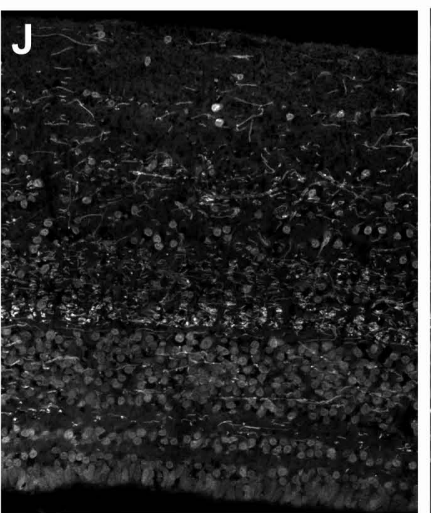

3w cut

6w cut

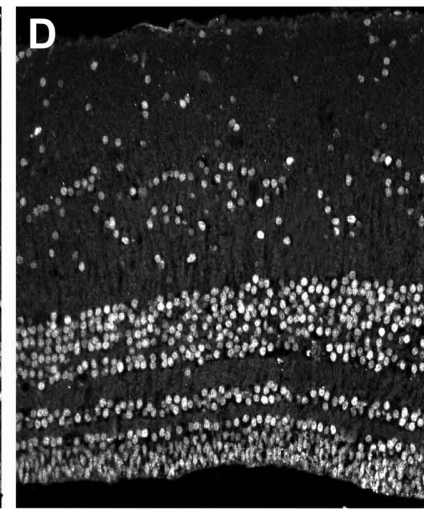

$\mathbf{H}$

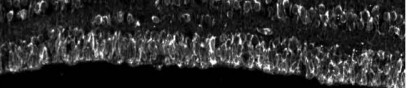

(t)

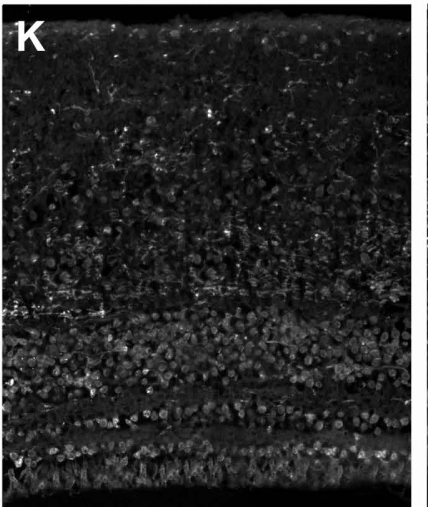

L

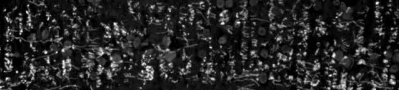


RAR $\alpha$

RAR $\beta$

RAR $\gamma$

GAPDH

52 kDa

$51 \mathrm{kDa}$

$50 \mathrm{kDa}$

$37 \mathrm{kDa}$

B

*

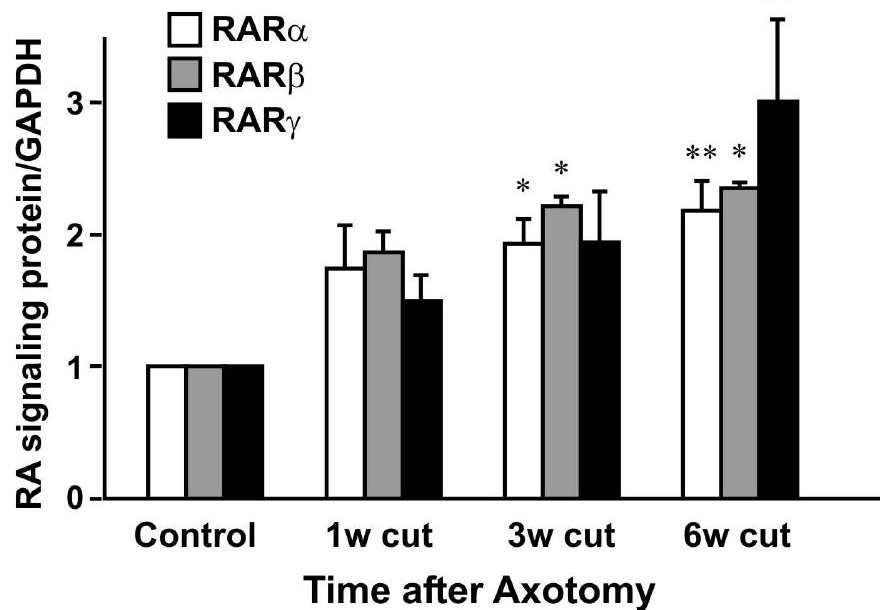

$\frac{1}{5}$
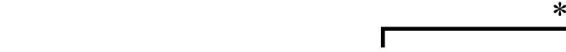

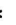

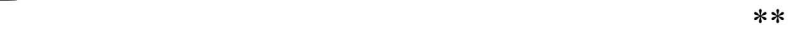

